\title{
FORMALIN OR OTHER FIXING VAPOUR FOLLOWED BY ABSOLUTE ALCOHOL AS A WET METHOD FOR BLOOD FILMS.
}

\author{
By the Hon. G. Scort, M.A., M.B. (Cantal).). \\ From the I'atholoyical Laboratory, Cambridyc.
}

Tire feature of this method is that by congulating the plasma of the spread film by a vapour fixative, before clropping it into the clehydrating solution, the red blood corpuscles are prevented from running together, while at the same time they regain their natural shape.

This method, although a very simple and rapid one, well suited for clinical work, gives results equal to any for detailed examination. The nuclei and all forms of grinules, coarse and fine oxyphile and basophile, as well as bacteria, are well shown.

It las been found by Ciulland ${ }^{1}$ that ilried films, when fixed in alssolute: alcohol, will stain only with hematoxylin and eosin, and not with the most useful group, the basic aniline dyes, methylene-hlue, etc. With roet films, however, absolute alcohol gives quite different ressults-il film of marrow fixed in alcohol stains perfectly and rapilly, with hoth the basio and the acid dyes. In this connection may be noted the unstained margin of a film, where it has dried in films, fixed and stained in the manner presently to be ilescribed.

On attempting to fix a wet bluod film in albsolute alcohol we are, however, at once met by a difticulty. If held in the vapour of alcohol for a few moments, the spreal tilm collects again into a drop; if the film is dropperl directly into the alcohol, the red corpuseles are seen under the microscope to have run together into groups, and it is impossible to get a well-spread film.

To overcome this difficulty, l'rofessur Woodhend suggrested the use of osmic acid or formic aldehycle vapour, to coagulate the plasma before dropping the film into the alcoliol. This was found to answer excellently, films being thus obtained which were perfect in spreading and in the shape of the individual real corpuscles; while by dropping the wet film into any fixing solution, even after waiting as long as possible before drying occurs for the corpuscles to regain their shape, some of the red corpuscles are usually drawn out or otherwise deformed. The shape of the white corpuscles is also perfectly pre-

${ }^{2}$ Scottish Med. and Surg. Journ., Edinburgl, April 1899. 
served; they do not show any shrinking, as they may do if the film is dropped directly into absolute alcohol (Gulland ${ }^{1}$ ).

The vapour of a 2 per cent. osmic acid solution in water gives as good results as those obtained with formalin; but the latter has the advantage of not being easily decomposed, and its vapour is not so irritating to the conjunctiva.

It may be well to briefly enumerate the several solutions used in making wet blood films:-

1. Professor Murr ${ }^{2}$. Saturated corrosive sublimate solution in normal salt solution.

2. Durham ${ }^{3}$

- $\left\{\begin{array}{l}\text { Rectified spirit } \\ \text { Saturated corrosive sublimate in normal } \\ \text { salt solution }\end{array}\right\} \begin{aligned} & \text { equal } \\ & \text { parts. }\end{aligned}$

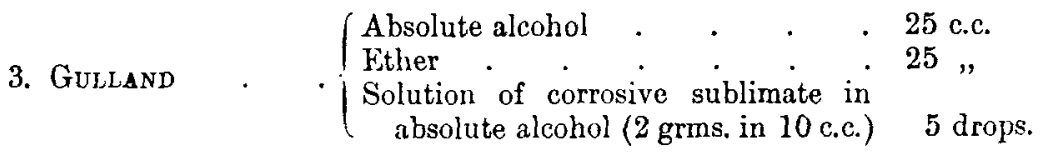

4. Nikiforoff ${ }^{4} \cdot\left\{\begin{array}{l}\text { Absolute alcohol } \\ \text { Ether }\end{array}\right\}$ equal parts.

5. Richard MIUIR ${ }^{j}$. Two per cent. solution of formalin in water ${ }^{b}$ made from the 40 per cent. solution. Orop the wet film into this and leave for five to ten minutes; transfer to 50 per cent. alcohol for fifteen ininutes or longer, wash in water and stain. More recently he has improved the method, and uses absolute instead of 50 per cent. alcohol.

In all these methods the film is dropped into a fixing solution. Ether or corrosive sublimate is added to the absolute alcohol. The vapour of formic aldehyde or osmic acid has been only used to fix films, which are then allowed to dry.

One object in view, however, was to obtain a fixative for wet blood films, which would give the most delicate results on staining with that most useful new class of stain, the combined basic and acid aniline dyes, first deseribed by L. Jenner, and further worked out and described by H. Rosin. ${ }^{8}$

Briefly the results obtained are:--That when saturited watery solutions of an acid and a basic dye are mixed, a precipitate is obtained, very bulky, if the correct proportions are observed, but partially or wholly dissolved if either the acid or the basic dye be adled in excess.

I Journ. Physiol., Cambridge and London, 1890, vol. xix. p. 388.

2 Journ. Anat. and Physiol., London, 1892, vol. xxvi. p. 393.

3 Joum. Path. "tul Bacteriol., Edinburgh and London, 1897, vol. iv. 1. 340.

- Brit. Med. Joum., London, 1897, vol. i. p. 652.

- Journ. Path. aud Bacteriol., Edinburgh and London, 1900, vol. vi. p. 395.

${ }^{5}$ I find the wet film apt to be washed off if dropped into 2 per cent. or any solution of formalin in water. Two per cent. of formalin solution in absolute alcohol answers better.

${ }^{7}$ Lancet, I Iondon, 1899 , vol. i. p. 370.

${ }^{8}$ Berl. klin. Wchnschr, 1899, p. 251. 
These precipitates are obtained by mixing watery solutions of-

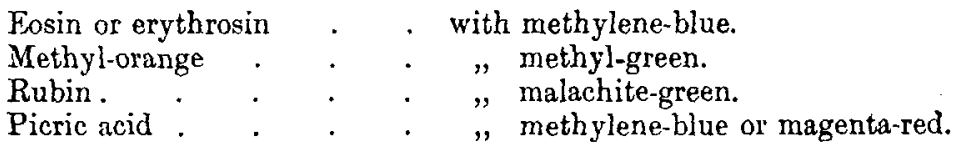

All these precipitates are of a crystalline nature, and while almost insoluble in water are quite soluble in absolute alcohol, and still more so in absolute methyl alcohol.

From these solutions they can be reobtained in crystalline form by (1) concentration of the solution, (2) addition of water.

The precipitates are compounds of the acid and the basic dye. Most of the mixtures of eosin and methylene-blue have been designed so as to avoid a precipitate on mixing or keeping. The differential staining results from decomposition of the compound by the elements of the tissues, the acid elements combining with the basic dye, and the basic elements with the acid dye. It is a distinct advantage in comparing different specimens that the proportion of the two stains should be constant, a result which it is difficult to obtain if two stains are used separately.

The most useful of the above is the eosin-methylene blue compound. Jenner's "fixative and stain for dry blood films" is made by shaking up 0.5 grm. of this powiter in 100 c.c. of pure methyl alcohol (E. Merck, "for analytical purposes"; the commoner varieties are apt to be acid) and filtering. This solution keeps well if stoppered. The stain may also be made up by mixing 125 c.c. of 0.5 per cent. solution of easin (Gribler's) with 100 e.c. of 0.5 per cent. solution of medicinal methylene-blue (Gribler's) in absolute methyl alcohol. It is simplest, however, to buy the solid compound substance and make up as above, or the solution ready for use. It is supplied by $R$ Kanthack, 18 Berners Street, London, W.

The method followed is-

1. Hold the wet fim, wet side down, in the mouth of a wide bottle half filled with ordinary 40 per cent. solution of formic aldehyde for about fice seconds.

2. Orop, while still wet, film downwards into absolute alcohol. Leave fifteen minutes, or, if more convenient, as long as forty-eight hours.

:3. Blot off excess of alcohnl, amd move cover-glass to a dry part of the blotting paper.

4. Immediately, before any drying occurs, drop on a few drops of the eosin-methyene-blue stain with a dropping pipette; cover with a watch glass to prevent evaporation and consequent precipitation; stain for two minutes, not any longer.

5. Allow excess of stain to run off the cover-glass, and rinse at once in a bowl of distilled water, and then in fresh distilled water.

6. Blot off excess of water.

7. Dehydrate very rapidly in absolute alcohol, merely dipping in and out as quickly as possible.

8. Wash off alcohol in first xylol rapidly; wash in second xylol; drop on fresh xylol.

3. Mount in xylol balsam. 


\section{REMARKS.}

The three most important points to attend to are-

1. Use only pure distilled water to wash off the excess of stain.

2. Dehydrate quickly enough in the absolute alcohol.

3. Use cover-glasses which are quite free from acid.

The film must on no account be allowed to dry at any stage. If it dries either before fixing in alcohol, or between fixing and staining, it does not take on the stain. If it dries after staining, the clear definition of the nucleus is lost.

The formalin can be entirely removed, so that it has no effect on the staining, by leaving the film in the bottle with alcohol for about an hour. If many films are on the top of each other, or it is wished to stain sooner, the formalin is removed by leaving the cover-glass film upwards in absolute alcohol in a capsule for fifteen minutes.

The effect of formalin, if not removed, is to make the red blood corpuscles stain slaty blue, though, provided that it is not present in excess, it only improves the staining of the colourless cells, acting as a mordant to the methylene-blue, and giving very clear nuclear staining without danger of excessive decolorisation during dehydration with absolute alcohol (Bolles Lee and Henneguy ${ }^{1}$ ), while the oxyphile granules stain well with the eosin.

It is necessary to blot off the excess of alcohol before staining, for dilution of the eosin-methylene-blue stain with alcohol makes the film stain only with the eosin and not with the methylene-blue. Staining for a longer time with this stain does not give deeper nuclear staining but results in feeble staining with the methylene-blue and overstaining with the eosin. A film will stain fairly well in ten seconds.

When washing off the excess of stain use sufficient water or a precipitate may occur. Do not leave the preparation in the first quantity of water or the spirit will decolorise the methylene-blue. If any stain has dried on the back of the cover-glass it can now be wiped off with a piece of wet blotting-paper. The alcohol must be washed off quickly in the first xylol or the alcohol will decolorise the methylene-blue. No trace of alcohol must be left or the methyleneblue may become decolorised after a few days.

Formalis has often been used to fix films, which are then allowed to dry. Milroy and Malcoln ${ }^{2}$ found that they had got the best results for their purpose with films fixed in formalin vapour for two or three minutes and dried, then stained in Chenzinsky's eosin-methylene-blue mixture for twentyfour hours at $40^{\circ} \mathrm{C}$. in a closed vessel. Benario places dried films in a mixture of-formalin 1, water 9 , and absolute alcohol, 90 parts, for one minute, then stains without drying. Gulland places dried films for five minutes in a mixture of 10 parts of formalin in 90 of absolute alcohol.

1 "Traité des méthodes techniques de l'anatomie microscopique," second edition, Paris, 1896, p. 135.

${ }^{2}$ Journ. Physiol., Cambridge and London, 1899, vol. xxv. p. 116. 
I prefer to use formalin which gives a neutral reaction with litmus, but though some of the solutions sold are decidedly acid, the vapour usually is neutral, and gives satisfactory results with blood films.

ABSOLUTE ALCOHOL. - The film is in absolute alcohol throughout fixing and staining. Milroy and Malcolm have shown that the fine and coarse oxyphile granules are not affected hy absolute alcohol. Hardy and Westbrook ${ }^{2}$ found that absolute alcohol was the only reagent which preserves all the varieties of cells. Kanthack and Hardy ${ }^{2}$ plunged wet films into alsolute alcohol, in order to preserve the tinely granular basophile cells of blood. Though varying in different animals and situations, the gramules of hoth coarse and finely granular hasophile cells are very sensitive to water, so the percentage of alcohol in basic staining should not fall below 80 , and rapid dehydration with absolute alcohol is essential to their preservation. Basophile cells will be found to be more numerous by this method, because the hasophile granules are well preserved. 95 per cent. spirit may be used instead of absolute alcohol after formalin vapour, but does not give quite as good nuclear staining or definition of fine oxyphile granules.

The best nuclear results are obtained by staining within two days; but differential connts can be made with films kept for two months in absolute alcohol hefore staining; the hyaline cells, however, lose their clear structure. Films cannot be kejt in 50 per cent. spirit, because the fine oxyphile granules then stain diftinely, and the muclei are not so well preserved. The film must not be washed in water or spirit before staining. As no corrosive sublimate is used no washing is required, and there is no possibility of it precipitate occurring.

The Fosin-NIetrylene-Blue Compound Stain. - There must be no trace of acid or alkali on the cover-glasses, which must be well cleaned (as by boiling in Van Frmengem's solution for fifteen minutes and stirring with a glass rod), washed in distilled water till no trace of acil remains on testing with litmus paper, kept in ahsolute alcohol, and burnt on clean wire gauze over a Bunsen, or spirit flame before use. The sides should also be clean.

With this stain the red blood corpuscles are terra-cotta. Nuclei are dark hlue, showing the nuclear network. The coarse and fine oxyphile granules are brilliant pink. The basophile gramles are dark violet. Bacteria, malarial parasites, and flariæe are dark hlue. The hest results are obtained at room temperature not lower than $15^{\circ} \mathrm{C}$.

Jenner's stain is violet-blue. If alkali be added it turns a pink violet colour and gives only the basic methylene-blue stain. If acid he added, it turns an intence blue colour and gives only the acid eosin stain. If a small trace only of alkali is added, the granules of the polymorphonuclear leucocytes remain unstained, and do not now take on the basic stain as they would do if truly neutrophile, while the granules of the coarsely granular oxyphile leucocytes still stain pink with eosine These reactions are best seen by treating the flim hefore staining with absolute alcohol, made either slightly alkaline or acid. This compound stain is thus a true nentral stain, very sensitive to both acid and basic reaction.

As pointel out by Ehrlich, when films are fixed in solutions containing corrosive sublimate, the oxyphile reaction is increased, and this is so in proportion to the amount of sublimate present. This stain can also be used with any of the wet methods mentioned above, if the films are taken from absolute aIcohol to staining. In those methods which require washing with water, or weaker strengths of spirit, the fine oxyphile granules become quite diffuse; the nuclei, though clearly outlined, are opaque, and hasophile gramules are not preserved well.

Other stains may be used, as-

'Journ. Physiol., Cambridge and Lonưon, 1895, vol. xviii. p. 491.

2 lbid, 1894, rol, x vii, fi. 94 . 
Hæmatein, or hæmatoxylin and eosin; Chenzinsky's eosin-methylene-blue mixture; eosin and methylene-blue separately, etc.

\section{Other FilMs.}

For most other films than blood the consistence of the fluid medium and greater adhesive property of the colourless cells, together with the small number of red blood corpuscles, makes it unnecessary to use formalin vapour, and the film may be fixed in absolute alcohol alone.

Wet marrow films stained in the eosin-methylene-blue stain for two minutes give beautiful specimens. Here the delicate marrow cells require a wet method even more than the more mature cells of blood, if the nucleus and disposition of the granules is to be observed. Since the films have been exposed only to the action of absolute alcohol during fixing, and as the solvent of the dye during staining, there is even less to interfere with the staining reaction of the granules than in the case of dry films fixed by heat. If the nucleated or other red blood corpuscles present are to be studied, formalin vapour may be used with advantage, as it prevents them from collecting into groups.

As a wet method for bacteriological work, for films containing cells, this method of fixing and staining gives excellent results. Bacteria are well stained and their position in the cells shown clearly. Methylene-blue and cosin are the best stains for this purpose, and with this method of fixing there is no fear of any precipitate of corrosive sublimate. Scrapings and smear preparations of organs may be treated in the same way as marrow films. Sputum and pus should be fixed for a longer time than blood, and also stained longer, about four minutes staining giving the best results. Formalin vapour need only be used for pus if it is very thin and serous, and many red blood corpuscles are present. Good results are obtained with recent pus where not too much fatty degeneration has taken place. In sputum the coarsely granular oxyphile cells are well shown, as also are bacilli, cocci, and diplococci.

Wet filme in general.-Wet films are equivalent to fluid preparations and can be stained better differentially. By gradually focussing from above down, views can be obtained at different focal planes, like a series of horizontal sections, and a good idea is gained of the shape and disposition of the nucleus and other structures within the cell.

Though a differential count can be made with a Zeiss $D$, obj., it is especially desirable to use a $\frac{1}{12}$ th in. oil immersion lens to examine cells fixed by a wet method, because the cells are spherical and therefore smaller, and are also more transparent than in the case of the flattened and more opaque cells of a dried film.

[The above method, worked out by Mr. Scott, has given excellent results; it has now been adopted for work in the Pathological Laboratory in Cambridge, and incorporated in the book of methods with which the students in the department are supplied.-G. S. W.] 